\title{
A formação continuada no cotidiano escolar
}

Recebido em 15.12.2015. Aprovado em 20.01.2016 Avaliado pelo sistema double blind review

Teresa Manfreda

ce132@sesisp.org.br

Centro Educacional SESI N. ${ }^{0} 132$ - São Caetano do Sul - SP - Brasil

\section{Resumo}

O Centro Educacional SESI $n^{0} 132$ oferece ensino fundamental de $1^{\circ}$ ao $5^{\circ}$ ano, atende a 472 alunos e está localizado na cidade que possui os melhores indicadores sociais de todo país e lidera o ranking das cidades mais desenvolvidas do Brasil, com o maior IDH - São Caetano do Sul-SP. Constatou-se em uma pesquisa de satisfação aplicada aos alunos, que $48 \%$ estavam insatisfeitos com relação às aulas e à explicação dos conteúdos pelos professores. Este dado associado aos resultados de desempenho pouco satisfatórios nas avaliações externas (SARESP) e nas avaliações internas da escola, observa-se que o processo ensinoaprendizagem necessita de aprimoramento com vistas a sua melhoria. A formação continuada em serviço é uma solução integrada que enfrenta as causas do problema e objetiva melhorar a qualidade das aulas com consequente melhoria das aprendizagens dos alunos. Extingue as fraquezas em curto prazo e o resultado esperado são aulas dinâmicas, com estratégias variadas, que desafiem as habilidades cognitivas dos alunos com consequente melhoria das aprendizagens e proficiências. O investimento necessário é de $R \$ 59.250,00$.

Palavras-chaves: Plano de Empreendimento. Empreendedorismo e Educação. Formação continuada. 


\section{Caracterização da Escola}

O Centro Educacional SESI N. ${ }^{0}$ 132, localizado em São Caetano do Sul (SP), foi fundado em 1964 e atende ao $1^{\circ}$ ao $5^{\circ}$ ano. A escola tem como missão "promover a Educação para o desenvolvimento econômico e social, contribuindo para a elevação da competitividade da indústria e melhoria dos padrões de qualidade de vida de seus trabalhadores e dependentes", e a visão de "ser líder no desenvolvimento social que apoia a competitividade da indústria e o crescimento sustentável da economia ".

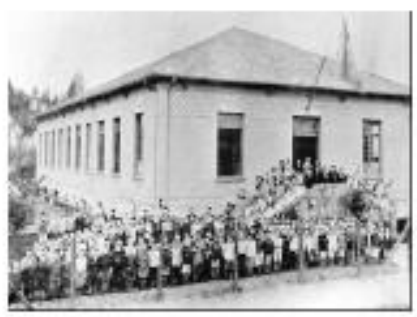

Grupo Escolar Senador Flaquer - 1925

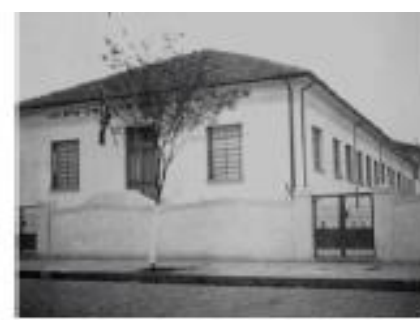

Grupo Escolar Senador Flaquer - 1965

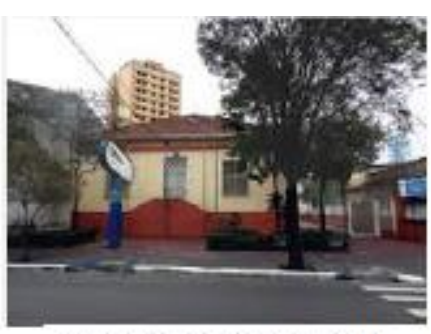

Centro Educacional SESI - 2015

\section{Instalações}

A escola dispõe de oito salas de aula, uma sala de leitura, uma sala de informática, um pátio descoberto, uma quadra coberta, um refeitório, quatro banheiros -masculino e feminino - para alunos e para funcionários, uma cozinha, uma secretaria escolar, uma sala para direção escolar e uma sala para professores, todas em bom estado de conservação.

\section{Breve histórico}

O quadro a seguir apresenta a relação dos acontecimentos mais relevantes para a evolução da escola, desde a fundação até hoje:

\begin{tabular}{|c|l|}
\hline \multicolumn{1}{|l|}{ Ano } & Acontecimentos relevantes \\
\hline 1920 & $\begin{array}{l}\text { Construção do prédio com investimento da comunidade, indústrias locais e } \\
\text { Governos Estadual e Municipal. }\end{array}$ \\
\hline 1925 & Início das atividades escolares sob responsabilidade do Governo Estadual. \\
\hline 1965 & Reforma do prédio e instalações \\
\hline 1981 & Início das atividades escolares do SESI-SP. \\
\hline 1993 & $\begin{array}{l}\text { Reforma da fachada, instalações internas, substituição das instalações } \\
\text { elétricas e cobertura da quadra. }\end{array}$ \\
\hline 2000 & Revitalização das instalações, implantação da sala de informática. \\
\hline 2010 & Implantação de lousas digitais em todas as salas de aula. \\
\hline
\end{tabular}

\section{Professores e funcionários}

A equipe é formada por quinze professores, distribuídos da seguinte forma:

\begin{tabular}{|l|c|}
\hline Disciplina / Área & Quant. de professores \\
\hline $1^{\circ}$ ano 3 & 3 \\
\hline $2^{\circ}$ ano 3 & 3 \\
\hline $3^{\circ}$ ano 3 & 3 \\
\hline $4^{\circ}$ ano 3 & 3 \\
\hline $5^{\circ}$ ano 3 & 3 \\
\hline Auxiliar Docente $1^{\circ} / 5^{\circ}$ ano & 1 \\
\hline
\end{tabular}


Todos os professores são efetivos no cargo e possuem graduação em pedagogia. Dos 16 professores, 4 possuem especialização em psicopedagogia 2 possuem mestrado. Além disso, a escola conta com um diretor escolar, dois coordenadores pedagógico e 8 apoio sendo um inspetor de alunos, um cozinheiro, dois auxiliares de cozinha, três auxiliares de serviços gerais e um porteiro.

\section{Perfil dos alunos}

Os alunos estão distribuídos por séries e turnos da seguinte maneira:

\begin{tabular}{|c|c|c|c|c|c|c|}
\hline \multirow{2}{*}{ Série/Ano } & \multirow{2}{*}{$\begin{array}{c}\text { Média de } \\
\text { idade }\end{array}$} & \multirow{2}{*}{$\begin{array}{c}\text { Total de } \\
\text { alunos }\end{array}$} & Manhã & \multicolumn{3}{|c|}{ Tarde } \\
\cline { 5 - 7 } & & & $\mathbf{N}^{0}$ alunos & $\mathbf{N}^{0}$ turmas & $\mathbf{N}^{0}$ alunos & $\mathbf{N}^{0}$ turmas \\
\hline $1^{0}$ ano & 6,2 & 96 & 32 & 1 & 64 & 2 \\
\hline $2^{0}$ ano & 7,6 & 94 & 30 & 1 & 64 & 2 \\
\hline $3^{\circ}$ ano & 8,3 & 95 & 31 & 1 & 64 & 2 \\
\hline $4^{0}$ ano & 9,5 & 91 & 61 & 2 & 30 & 1 \\
\hline $5^{\circ}$ ano & 10,4 & 96 & 64 & 2 & 32 & 1 \\
\hline TOTAL & - & 472 & $\mathbf{2 1 8}$ & $\mathbf{7}$ & 254 & $\mathbf{8}$ \\
\hline
\end{tabular}

Os alunos são oriundos da zona urbana (100\%) cujos pais trabalham na economia formal $(88 \%)$ e informal (12\%). Aproximadamente $5 \%$ dos alunos de $4^{\circ}$ e $5^{\circ}$ ano auxiliam seus pais no trabalho da economia informal, antes ou após o horário escolar. Os alunos residem na própria cidade que estudam (96\%), em casas térreas ou assobradadas (34\%) e os demais em apartamento (66\%), numa distância média da escola de $1,3 \mathrm{~km}$. Os professores e funcionários são ingressantes por seleção pública, nos respectivos cargos e são moradores na cidade onde trabalham (73\%) e cidades vizinhas (27\%). Os alunos participam dos eventos escolares, são empenhados nas atividades de olimpíadas do conhecimento (LP e MA) que ocorrem anualmente na escola, porém, apresentam baixo empenho nas lições de casa. Os pais trabalham (89\%) e há pouco investimento no acompanhamento da vida escolar de seus filhos e nas atividades escolares. Há duas festas culturais durante o ano, promovidas pela Prefeitura, com danças folclóricas, gastronomia ritos e celebrações aos santos padroeiros da cidade, organizadas pelos gestores escolares e equipe técnica das Secretarias Municipal de Cultura e Educação.

\section{Características do entorno}

A escola está localizada numa cidade de $15.331 \mathrm{~km} 2,149.263$ habitantes, dista a 1,4 km do centro, em um bairro de classe média. A cidade de São Caetano do Sul possui a maior parte da economia centrada em serviços, seguida de indústrias como a General Motors do Brasil, esta última é o maior centro financeiro da cidade. Possui os melhores indicadores sociais de todo país e lidera o ranking das cidades mais desenvolvidas do Brasil, com o maior IDH - 0,862 - numa escala de 0 a 1 (PNUD/2010). A maioria dos moradores é descendentes de italianos, espanhóis e portugueses. Apesar de não haver favelas, o município possui parte da população vivendo precariamente, em cortiços, apesar de todo desenvolvimento. Próximo a escola há dois vilarejos com cortiços e cerca de $3 \%$ dos alunos são oriundos destes. 0 bairro dispõe de linhas de ônibus e trem que interligam o município com as cidades vizinhas. É baixo o índice de vulnerabilidade à violência na cidade, observa-se aumento de demanda de vagas nos últimos quatro anos e um dos fatores é o crescimento imobiliário da cidade. Nos últimos seis anos foram construídos três edifícios residenciais no bairro e 156 na cidade. 


\section{Identificação do Problema e da Oportunidade}

A identificação do problema partirá de um diagnóstico da Unidade Escolar. Para isso, foi observada a principal avaliação externa (SARESP), avaliações da equipe pedagógica, bem como relatórios internos de desempenho.

\section{SARESP}

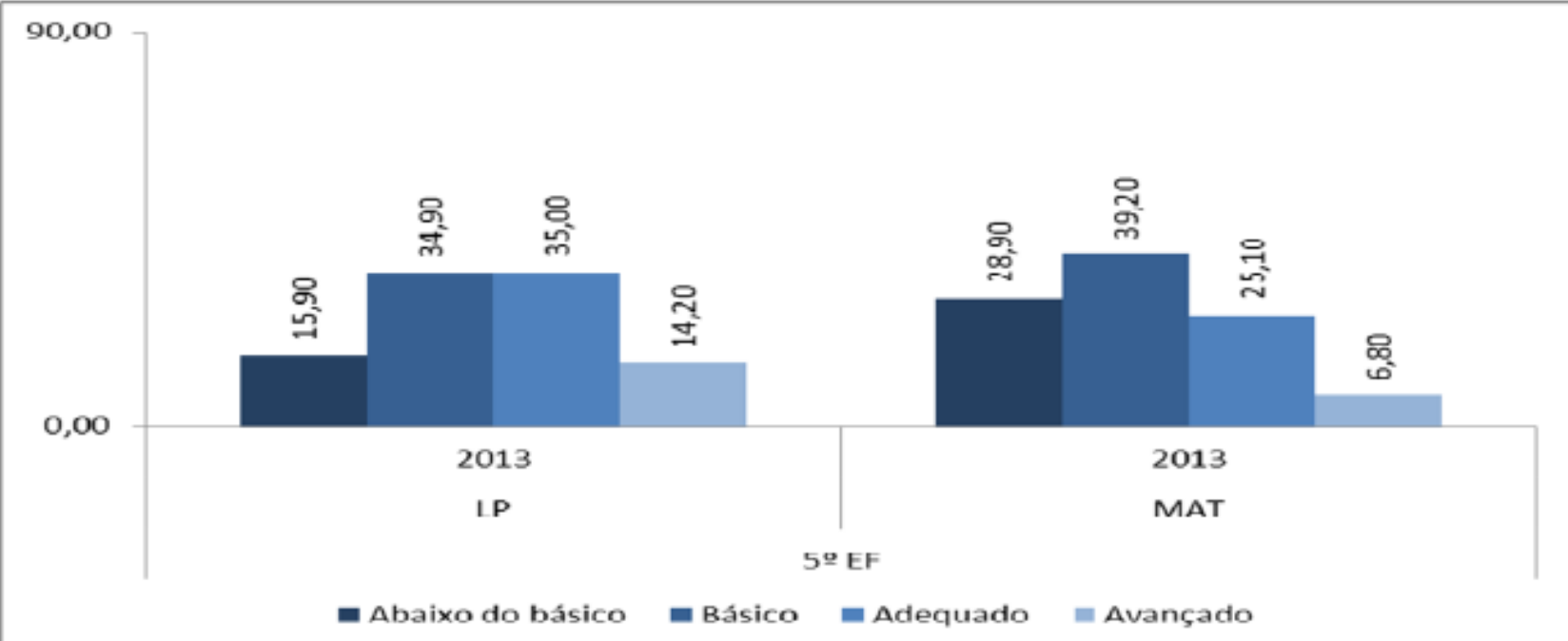

Gráfico 1: SARESP 2013 - Distribuição percentual de alunos nos níveis de proficiências das disciplinas de Língua Portuguesa e Matemática, $5^{\circ}$ ano EF

Fonte: VUNESP

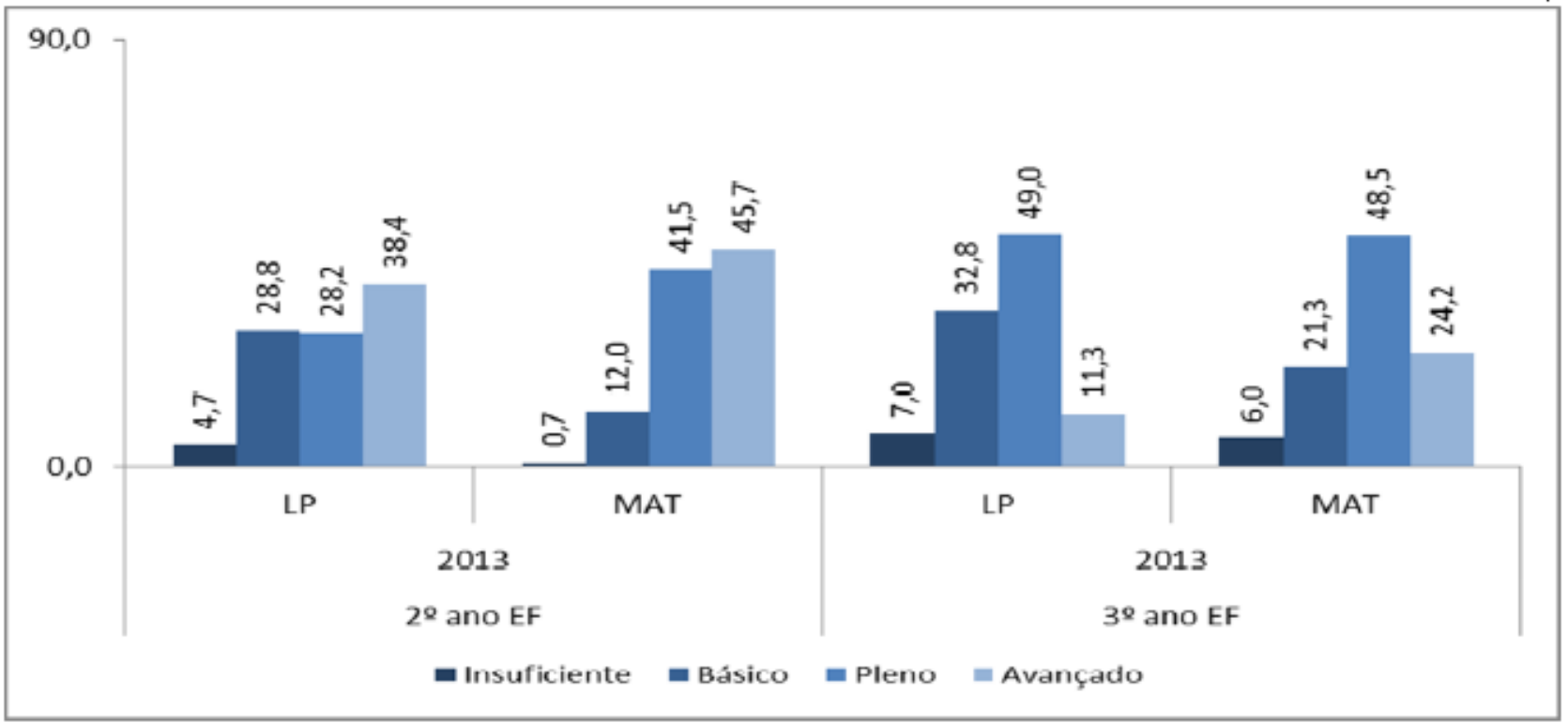

Gráfico 2: SARESP 2013 - Distribuição percentual dos alunos nos níveis de proficiências das disciplinas de Língua Portuguesa e Matemática, $2^{\circ}$ e $3^{\circ}$ ano EF.

\section{Fonte: VUNESP}

Os dados revelam que o desempenho dos alunos no $2^{\circ}$, em LP é superior, comparado aos de $3^{\circ}$ e $5^{\circ}$ ano. À medida que são agregadas mais competências cognitivas, exigindo níveis mais complexos de aprendizagem, menor é o desempenho, conforme se pode observar no nível Avançado. No $2^{\circ}$ ano, $38,4 \%$ dos alunos 
encontram-se no referido nível. No $3^{\circ}$ ano o percentual diminui para $11,4 \%$ e $14,2 \%$ no $5^{\circ}$ ano. Esta queda é ainda mais acentuada em MA, considerando que este componente curricular exige habilidades relacionadas à resolução de problemas, vinculadas às habilidades de leitura e interpretação de texto. No $2^{\circ}$ ano há $45,7 \%$ dos alunos no nível avançado, no $3^{\circ}$ ano esse índice cai para $24,2 \%$ e no $5^{\circ}$ ano apenas $6,8 \%$ dos alunos desenvolveram habilidades mais sofisticadas e demonstram ter um aprendizado superior ao esperado ao seu ano escolar.

\section{Avaliações e relatórios internos}

Apresentamos a seguir dados referentes ao número de matriculas inicial, movimentação de alunos e rendimento escolar dos anos iniciais do Ensino Fundamental. Tais dados, associados aos resultados do Conselho de Classe Final da unidade, constituem-se em elementos valiosos para detectar problemas, definir encaminhamentos, analisar variáveis e definir metas.

\begin{tabular}{|c|c|c|c|c|c|c|c|}
\hline $\begin{array}{c}\text { Sériel } \\
\text { Ano }\end{array}$ & $\begin{array}{c}\text { Matrículas } \\
\text { iniciais }\end{array}$ & Evasão & Transf. & $\begin{array}{c}\text { Matrículas } \\
\text { finais }\end{array}$ & Aprov. & Reprov. & $\begin{array}{c}\text { Percentual } \\
\text { de } \\
\text { reprovação } \\
\text { no ano }\end{array}$ \\
\hline $1^{\circ}$ ano & 96 & 0 & 2 & 94 & 92 & 2 & \multirow{2}{*}{3,1} \\
\hline $2^{\circ}$ ano & 96 & 0 & 2 & 94 & 93 & 1 & \\
\hline $3^{\circ}$ ano & 96 & 0 & 3 & 93 & 90 & 3 & \\
\hline $4^{\circ}$ ano & 96 & 0 & 1 & 95 & 91 & 4 & \\
\hline $5^{\circ}$ ano & 96 & 0 & 4 & 92 & 88 & 4 & \\
\hline
\end{tabular}

\section{Principais problemas identificados}

Com base nos dados do SARESP, da pesquisa de satisfação dos alunos e nos resultados de avaliações internas da escola, observa-se que o processo ensinoaprendizagem necessita de aprimoramento com vistas a sua melhoria. Os dados da avaliação externa revelam que alunos do $5^{\circ}$ ano possuem desempenho inferior quando comparados aos alunos de $2^{\circ}$ e $3^{\circ}$. À medida que são agregadas mais competências cognitivas, exigindo níveis mais complexos de aprendizagem, menor é o desempenho, conforme se pode observar no nível avançado, isto é, o ensino não favorece o desenvolvimento de tais competências/habilidades. 0 percentual de reprovação é maior nos últimos anos do ensino fundamental I e coincide com os resultados de menor desempenho no SARESP. A pesquisa de satisfação revela que $48 \%$ dos alunos estão insatisfeitos com relação à explicação dos conteúdos pelos professores. Estes resultados associados aos acompanhamentos da prática docente, realizados pelo coordenador pedagógico, evidenciam a baixa qualidade das aulas ministradas pelos docentes, vez que poucos variam suas estratégias de ensino, não privilegiam o ensino por meio das didáticas de cada componente curricular, não observam a aprendizagem como um processo e, por conseguinte realizam a avaliação da aprendizagem de maneira fragmentada. Sobre o problema da avaliação fragmentada é confirmada ao se observar, por exemplo, a inconsistência entre 0 percentual de alunos reprovados $(3,1 \%)$ e a distribuição percentual dos alunos nos níveis de proficiência do SARESP em Língua Portuguesa. No $2^{\circ}$ ano, 33\% dos alunos possuem 0 nível de proficiência entre insuficiente e básico. No $3^{\circ}$ ano este percentual salta para $40 \%$ e no $5^{\circ}$ ano para $50 \%$, conforme se pode observar nos gráficos 1 e 2 . 


\begin{tabular}{|l|c|c|c|c|c|}
\hline \multicolumn{1}{|c|}{ Problemas } & G & U & T & GxUxT & Prioridade \\
\hline $\begin{array}{l}\text { Ausência de variação nas estratégias } \\
\text { de ensino }\end{array}$ & 5 & 5 & 3 & 75 & $2^{0}$ \\
\hline $\begin{array}{l}\text { Realização de avaliação da } \\
\text { aprendizagem de maneira fragmentada }\end{array}$ & 4 & 5 & 3 & 60 & $3^{0}$ \\
\hline $\begin{array}{l}\text { Ausência de projeto de formação } \\
\text { continuada em serviço para docentes }\end{array}$ & 5 & 5 & 4 & 80 & $1^{0}$ \\
\hline
\end{tabular}

\section{Detalhamento do problema}

Utilizou-se o Diagrama de Causa e Efeito para detalhar o problema:

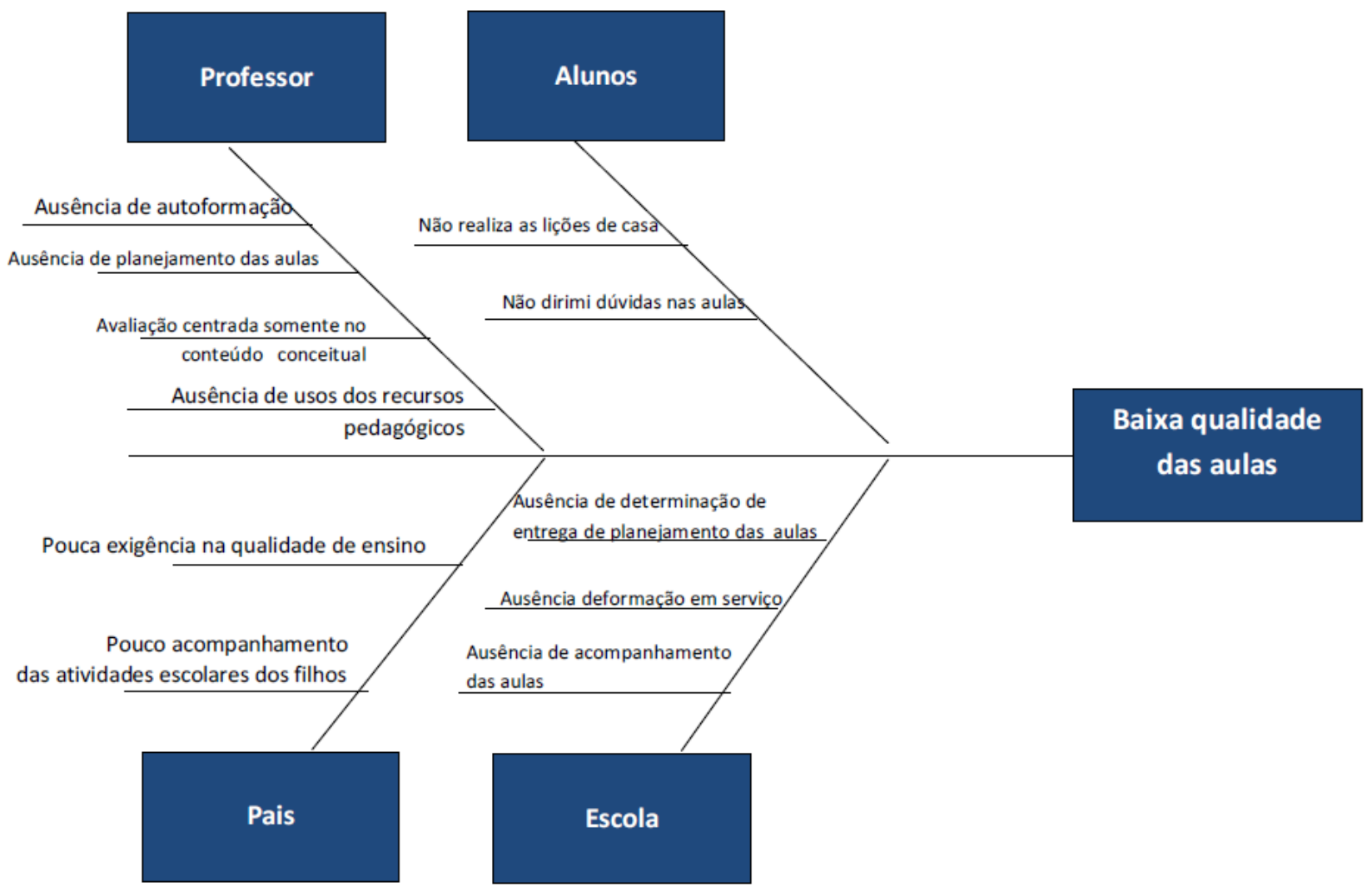




\section{Teresa Manfreda}

\section{Análise SWOT}

A partir das pesquisas realizadas pela equipe escolar e das discussões sobre o contexto da escola, foi desenvolvida a seguinte Matriz SWOT.

\begin{tabular}{|c|c|c|}
\hline & Aspectos favoráveis & Aspectos desfavoráveis \\
\hline \multirow[b]{2}{*}{ 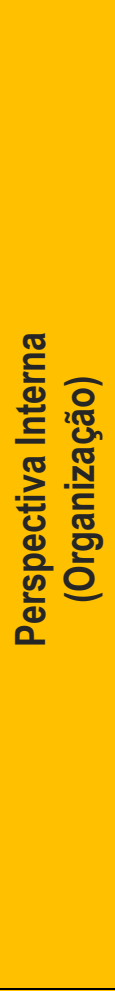 } & FORÇAS & FRAQUEZAS \\
\hline & $\begin{array}{l}\text { - } \text { Constância do corpo docente na } \\
\text { - } \text { mesma escola } \\
\text { ou mais de profissão } \\
\text { - Todos os docentes graduados } \\
\text { - Infraestrutura escolar adequada e } \\
\text { conservada } \\
\text { - Variedade de recursos pedagógicos } \\
\text { - Salas de aula equipadas com lousas } \\
\text { - } \text { digitais } \\
\text { - } \text { constante de funcionário completo e } \\
\text { - } \text { Alunos sem desvio idade-série } \\
\text { - Realização de recuperação da } \\
\text { aprendizagem em período contrário ao } \\
\text { horário de estudo dos alunos }\end{array}$ & $\begin{array}{l}\text { - Atividades em sala de aula nem } \\
\text { sempre interessantes e desafiadoras. } \\
\text { - } \text { Professores não fazem uso dos } \\
\text { recursos pedagógicos disponíveis } \\
\text { - } \text { Professores não fazem autoformação } \\
\text { para aperfeiçoamento profissional. } \\
\text { - Ausência de planejamento das aulas } \\
\text { pelos docentes e acompanhamento da } \\
\text { Direção } \\
\text { - Ausência de formação em serviço }\end{array}$ \\
\hline \multirow[b]{2}{*}{ 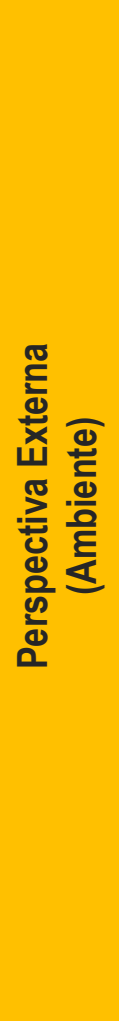 } & OPORTUNIDADES & AMEAÇAS \\
\hline & $\begin{array}{l}\text { - Indústrias da cidade que apoiam } \\
\text { programas educacionais das escolas } \\
\text { do município } \\
\text { - } \quad \text { Parceria com a Fundação NOVO } \\
\text { BRASIL - Programa de Melhoria da } \\
\text { Aprendizagem nas Escola } \\
\text { - Parceria com a Secretaria Municipal de } \\
\text { Educação para integração dos } \\
\text { currículos escolares da Educação } \\
\text { Infantil da Prefeitura com o } 1^{\circ} \text { ano do } \\
\text { EF do SESI. } \\
\text { A diversidade de etnias na cidade } \\
\text { propicia o estudo de usos, costumes, } \\
\text { tradições e culturas. } \\
\text { A Universidade Municipal de Educação } \\
\text { de SCSul. oferece parceria para } \\
\text { serviço social e apoio para alunos com } \\
\text { dificuldades de aprendizagem. }\end{array}$ & $\begin{array}{l}\text { - Alunos ingressantes no } 1^{0} \text { ano, } \\
\text { originários de Escolas de Educação } \\
\text { Infantil Municipal, com pouco requisito } \\
\text { para o ano de escolaridade. } \\
\text { - Transferência de alunos do } 2^{\circ} \text { ao } 5^{\circ} \\
\text { ano, oriundos de escolas municipais, } \\
\text { cuja organização do ensino é por meio } \\
\text { de progressão continuada e os alunos } \\
\text { não apresentam as competências } \\
\text { esperadas para o respectivo ano de } \\
\text { escolaridade. } \\
\text { Pais trabalham em período integral e } \\
\text { pouco se dedicam à vida escolar dos } \\
\text { filhos e pouco participam das } \\
\text { atividades escolares. }\end{array}$ \\
\hline
\end{tabular}


Observa-se que a escola possui mais forças e oportunidades, quando comparada às fraquezas e ameaças.

Na perspectiva interna da organização a escola possui infraestrutura adequada e conservada, constância dos docentes na mesma escola, tempo de magistério, ausência de distorção idade-série, evasão escolar e diversidade de recursos pedagógicos. Estes fatores colaboram para a melhoria das aprendizagens na escola.

Na perspectiva externa, o apoio das indústrias da cidade e a parceria com a Fundação Novo Brasil, será possível desenvolver um programa de formação continuada em serviço para os docentes com vistas a aprimorar suas práticas pedagógicas e melhorar a qualidade das aulas.

\section{Ações corretivas}

Visando preparar a organização para o desenvolvimento do projeto, no intuito de combater as fraquezas e reduzir os possíveis impactos das ameaças, foram definidas as seguintes ações:

- Formar o coordenador pedagógico em serviço para realizar análise e intervenções na prática docente.

- Estabelecer um programa de formação continuada em serviço para os docentes, a partir da elaboração de um diagnóstico das suas necessidades formativas.

- Estabelecer, para os professores, data para entrega do planejamento bimestral das aulas.

- Estabelecer, para o coordenador pedagógico, cronograma para análise dos planejamentos e devolutiva sistematizada aos docentes.

- Realizar reuniões periódicas com a Secretaria da Educação do município com vistas a aproximar o currículo da Educação Infantil das escolas municipais com o currículo do Ensino Fundamental do SESI, utilizando-se dos Parâmetros Curriculares Nacionais para mediar os estudos.

- Reorganizar os horários de reuniões de pais de modo que os mesmos possam comparecer à escola antes ou após seus expedientes de trabalho.

- Enviar aos pais, por meio eletrônico, as lições de casa estabelecidas para seus filhos.

- Estabelecer parceria com a Fundação NOVO BRASIL para desenvolver o programa de formação continuada em serviço com os docentes, com vistas a melhoria das aulas e consequente melhoria das aprendizagens dos alunos.

- Firmar parceria com a Universidade Municipal para realização de acompanhamento psicopedagógico e psicológico para alunos com dificuldades de aprendizagem.

\section{Oportunidade identificada}

A formação continuada de docentes é uma estratégia potente para o aprimoramento do processo ensinoaprendizagem. A Fundação NOVO BRASIL, por meio do Programa - Melhoria das Aprendizagens nas Escolas é um meio para realizar parceria com a Universidade Municipal de São Caetano do Sul, de modo aprimorar as práticas existentes em sala de aula. Professores capacitados em serviço terão oportunidade de ampliar suas estratégias de ensino, rever suas práticas em sala de aula, aprender a explorar os recursos pedagógicos disponíveis na escola. A formação continuada em serviço é uma solução integrada que enfrenta as causas do problema de baixa qualidade das aulas. A proposta tende a extinguir as fraquezas em curto prazo e o resultado esperado são aulas dinâmicas, com estratégias variadas, que desafiem as habilidades cognitivas dos alunos com consequente melhoria das aprendizagens e proficiências. 


\section{Detalhamento do produto/serviço e/ou processo}

\section{Foco do projeto}

O Projeto FORMAÇÃO CONTINUADA NO COTIDIANO ESCOLAR atenderá a todos os anos de escolaridade, todos os docentes e impactará em todos os alunos da unidade escolar. Tem como objetivo melhorar a qualidade das aulas oferecidas pelo Centro Educacional SESI 132 com consequente melhoria das aprendizagens dos alunos e fundamenta-se nos Princípios e Fins da Educação Nacional, Lei n 9.394 , de 20 de dezembro de 1996.

Art. $3^{\circ}$. 0 ensino será ministrado com base nos seguintes princípios:

IX - garantia de padrão de qualidade;

\section{Etapas do projeto}

O projeto será composto por 4 etapas:

- Diagnóstico das necessidades

- Estabelecimento de parcerias

- Operacionalização

- Avaliação

\section{Etapa 1 - Diagnóstico das necessidades}

Objetivo: Identificar as fragilidades pedagógicas na prática de todos os docentes da escola. Impacto na aprendizagem: Esta etapa não possui impacto direto nos alunos.

Atividades a serem realizadas: Questionário aos docentes com questões para identificação de dificuldades de ordem conceitual dos conteúdos previsto no currículo de todas as séries e de ordem metodológica do ensino.

\section{Atividade 1.1}

Descrição: A partir do Projeto Político Pedagógico da escola será elaborado questionário com questões abertas e de múltiplas escolhas, com justificativa da escolha. Será realizado pré-teste com os docentes da escola EMEF Senador Flaquer, no mesmo bairro, com o intuito de eliminar falhas na elaboração dos itens. A elaboração dos itens e a aplicação do pré-teste serão auxiliadas pelo Estatístico cedido pela Universidade Municipal de Educação de SCSul. da cidade. Finalizada a elaboração e ajustes após pré-teste, o questionário será aplicado em todos os docentes, simultaneamente, no horário de HTPC e serão informados previamente do objetivo e cumprimento desta etapa do projeto. Após a aplicação, os dados serão tabulados e categorizados com auxílio do profissional estatístico.

Duração: 30 dias

Recursos necessários: folhas de sulfite, impressora, computador.

Equipe envolvida: Gestores escolares e docentes da escola EMEF Senador Flaquer, gestores e docentes do CE SESI 132 e estatístico da Universidade Municipal de Educação de SCSul.

\section{Atividade 1.2}

Descrição: De posse dos dados, serão analisados os resultados nas categorias:

- Domínio do conteúdo a ser ensinado

- Metodologia de ensino

De acordo com os resultados do questionário, serão definidos os profissionais da educação, especializados nos conteúdos identificados, para desenvolver a formação dos docentes. 
Duração: 30 dias

Recursos necessários: computador

Equipe envolvida: Diretor e Coordenador Pedagógico, Especialistas em Educação da Universidade Municipal de Educação de SCSul.

\section{Etapa 2 - Estabelecimento de parcerias}

Objetivo: Estabelecer parcerias com a Fundação Novo Brasil e Universidade Municipal de Educação Superior Impacto na aprendizagem: Esta etapa não possui impacto direto nos alunos

Atividades a serem realizadas: Participar do processo de seleção da Fundação Novo Brasil e reunião com a Direção do Universidade de Educação Superior do município de São Caetano do Sul.

\section{Atividade 2.1}

Descrição: Cumprir as etapas descritas no Edital 11 - Projetos Inovadores em

Educação, da Fundação Novo Brasil.

Duração: 45 dias

Recursos necessários: não há

Equipe envolvida: Diretor Escolar do CE SESI 132

\section{Atividade 2.2}

Descrição: Apresentar, à Direção da Universidade Municipal de Educação de SCSul, o diagnóstico das necessidades formativas dos docentes, para identificar as possibilidades de parceria para o desenvolvimento das Formações com os docentes, monitoramento e avaliação do projeto de Formação Continuada no Cotidiano Escolar.

Duração: 30 dias

Recursos necessários: não há

Equipe envolvida: Diretor Escolar do SESI e Direção da Universidade Municipal de Educação de SCSul.

\section{Etapa 3 - Operacionalização}

Objetivo: Realizar, em parceria com a Universidade Municipal de São Caetano do Sul, a formação continuada dos docentes, visando oferecer subsídios para aprimoramento das práticas pedagógicas.

Impacto na aprendizagem: À medida que os docentes participam das formações, colocarão em prática os assuntos discutidos, sob a supervisão da gestão escolar do SESI, em parceira com a Universidade Municipal de Educação de São Caetano do Sul e, consequentemente, haverá melhoria nas aprendizagens.

Atividades a serem realizadas: Encontros de $2 \mathrm{~h}$ semanais com os docentes, durante o horário de HTPC, para estudos e tematização de práticas pedagógicas. A partir do Programa de Formação elaborado de acordo com o diagnóstico das necessidades formativas dos docentes, serão realizados encontros semanais, com $1 \mathrm{~h}$ de duração cada, no horário de HTPC, exceto nos meses de janeiro, julho e dezembro, em parceria com a Universidade Municipal de Educação de SCSul.

O programa de formação será dividido em 3 etapas, com duração de 4 meses cada.

$1^{\text {a }}$ etapa: A metodologia de ensino e os impactos na aprendizagem

$2^{\mathrm{a}}$ etapa: Cada aluno aprende de um modo e o ensino deve considerar essa diversidade.

$3^{\text {a }}$ etapa: A avaliação formativa no contexto do processo de ensino-aprendizagem

Cada etapa compreende os encontros semanais de formação e o monitoramento da prática em sala de aula 
com o objetivo de avaliar os impactos dos estudos.

\section{Atividade 3.1}

Descrição: Na $1^{\text {a }}$ etapa do projeto serão desenvolvidos 12 encontros semanais com $1 \mathrm{~h} 30$ de duração cada. 0 tema será: A metodologia de ensino e os impactos na aprendizagem. Nesta etapa pretende-se que os docentes analisem diferentes práticas pedagógicas utilizadas na escola e identifiquem a concepção de ensino que as embasa, conscientemente ou não e os impactos que ocasionam no sucesso ou fracasso das aprendizagens.

\section{Duração: 4 meses}

Recursos necessários: Sala de treinamento, projetor multimidia, flip shart e tablets com acesso a internet.

Equipe envolvida: Docentes e Coordenadores Pedagógicos do CE SESI 132, profissionais da Educação da Universidade Municipal de Educação de SCSul.

\section{Atividade 3.2}

Descrição: $\mathrm{Na} 2^{\mathrm{a}}$ etapa do projeto serão desenvolvidos 12 encontros com $1 \mathrm{~h}$ semanal de duração cada. 0 tema será: Cada aluno aprende de um modo e o ensino deve considerar essa diversidade.

Nesta etapa pretende-se que os docentes discutam as diferentes maneiras de aprender e como as estratégias colaboram para que todos os alunos tenham as mesmas oportunidades no desenvolvimento das suas habilidades e competências..

Duração: 4 meses

Recursos necessários: Sala de treinamento, Datashow, flip shart e tablets com acesso a internet.

Equipe envolvida: Docentes e Coordenadores Pedagógicos do CE SESI 132, profissionais da Educação da Universidade Municipal de Educação de SCSul.

\section{Atividade 3.3}

Descrição: $\mathrm{Na} 3^{\mathrm{a}}$ etapa do projeto serão desenvolvidos 12 encontros com $1 \mathrm{~h}$ semanal de duração cada. 0 tema será: A avaliação formativa no contexto do processo de ensino-aprendizagem

Nesta etapa pretende-se que os docentes reconheçam os princípios da avaliação formativa e como são colocados em prática na sala de aula de modo a favorecer as aprendizagens.

Duração: 4 meses

Recursos necessários: Sala de treinamento, projetor multimidia, flip shart e tablets com acesso a internet.

Equipe envolvida: Docentes e Coordenadores Pedagógicos do CE SESI 132, profissionais da Educação da Universidade Municipal de Educação de SCSul.

\section{Etapa 4 - Avaliação}

Objetivo: Verificar os impactos da formação continuada na prática docente.

Impacto na aprendizagem: Autonomia nas resoluções de problemas no cotidiano escolar, utilizando-se dos conhecimentos construídos e não memorizados.

Atividades a serem realizadas: Aplicação de 3 avaliações envolvendo as operações mentais condizentes com cada faixa etária, utilizando-se a matriz de referência da

Prova Brasil para elaboração dos itens.

\section{Atividade 4.1}

Descrição: Elaboração e aplicação de 2 avaliações envolvendo as operações mentais condizentes com cada faixa etária, utilizando-se a matriz de referência da Prova Brasil para elaboração dos itens. 
Recursos necessários: folhas de sulfite, computador, impressora

Equipe envolvida: Gestores Escolares do SESI, Especialistas em Educação da Universidade Municipal de Educação

\section{Casos de sucesso}

Nome do Projeto: Formação de professores: um exemplo de formação continuada

Nome da organização: Escola Estadual Romeu de Moraes

Local: São Paulo - Zona Oeste

Período em que foi realizado: 2009 a 2012

Breve relato do contexto anterior ao projeto: Para o desenvolvimento de suas aulas os docentes baseavam-se em suas experiências escolares, quando alunos. Exemplo disso é a correção de provas. 0 erro não era entendido como parte do processo de aprendizagem e indicador para o professor refletir sobre sua prática. Relatam que a formação inicial pouco contribuiu para aprenderem sobre didática.

Principais atividades desenvolvidas: Há quatro anos a escola desenvolve um projeto de formação continuada em parceria com a Escola da Vila, instituição privada, e com a Associação Parceiros da Educação, uma OCSIP - Organização da Sociedade Civil de Interesse Público.

Resumo dos principais resultados alcançados: Revisão de estratégias em sala de aula, como por exemplo, trabalhos em grupo, os quais passaram a ser uma organização intencional do professor com objetivo de fazer todos os alunos produzirem e colocarem em jogo seus conhecimentos, em colaboração; elaboração de atividades intencionais para aplicação em sala de aula; trabalhar o erro do aluno como processo e indicador para análise do trabalho do professor e realizar registros das aulas para reflexão sobre a prática.

Fonte: UNIVESP - Formação de professores: um exemplo de formação continuada.

https://www.youtube.com/watch?v=8s6dNzSOFoE

Acesso em 09 out. 2015.

\section{Novidade trazida pelo projeto}

\section{O projeto FORMAÇÃO CONTINUADA NO COTIDIANO E}

SCOLAR distingue-se dos projetos pesquisados por conter um programa de formação, isto é, um percurso formativo determinado a partir das necessidades identificadas com o corpo docente. Esta é a singularidade deste projeto. Os conteúdos previstos no programa foram dispostos de maneira a seguir uma lógica didática de desenvolvimento de modo a realizar os estudos e discutir sua aplicabilidade, proporcionando a possibilidade de reconstrução da prática pedagógica. 


\section{Teresa Manfreda}

\section{Cronograma de execução}

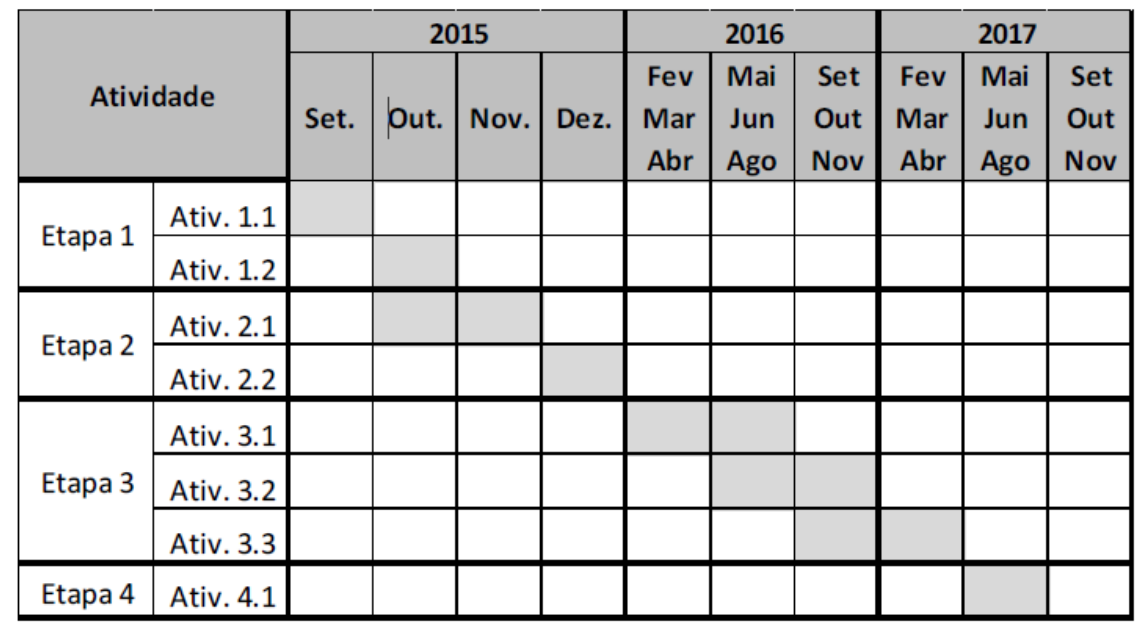


Gestão Estratégica Objetivos Estratégicos

\begin{tabular}{|c|c|c|c|}
\hline OBJETIVO & META & INDICADOR & ACOMPANHAMENTO \\
\hline \multirow{3}{*}{$\begin{array}{l}\text { Fortalecer a } \\
\text { participação } \\
\text { dos pais na } \\
\text { vida escolar } \\
\text { dos filhos }\end{array}$} & $\begin{array}{l}\text { Ampliar em } 30 \% \text { a participação } \\
\text { dos pais às reuniões bimestrais } \\
\text { em 2016, em } 40 \% \text { em } 2017 \text { e em } \\
60 \% \text { em } 2018 .\end{array}$ & Listas de presença das reuniões. & $\begin{array}{l}\text { Reuniões bimestrais com membros do } \\
\text { Conselho de Escola } \\
\text { Reuniões trimestrais com os membros da } \\
\text { Associação de Pais e Mestres }\end{array}$ \\
\hline & $\begin{array}{l}\text { Implementar a partir de } 2016 \text { a } \\
\text { comunicação com os pais por } \\
\text { meio de mensagens eletrônicał } \\
\text { via celular }\end{array}$ & $\begin{array}{l}\text { Controle com o } \mathrm{n}^{\circ} \text { de } \\
\text { respondentes às demandas } \\
\text { enviadas por telefone. }\end{array}$ & $\begin{array}{l}\text { Verificar a clareza das mensagens e a } \\
\text { antecedência da postagem de modo a facilitar } \\
\text { a organizaçção dos pais para as providências } \\
\text { cabíveis, quando necessário. }\end{array}$ \\
\hline & $\begin{array}{c}\text { Implementar em } 2016 \text { o Programa } \\
\text { Escola Aberta - duas vezes no ano } \\
\text { os pais participarão das aulas } \\
\text { regulares, juntamente com seus } \\
\text { filhos } \\
\end{array}$ & $\begin{array}{c}\text { Controle de presença no diário } \\
\text { de classe. } \\
\text { Pesquisa de satisfação, com os } \\
\text { pais e alunos. }\end{array}$ & $\begin{array}{c}\text { Verificar o planejamento das atividades de } \\
\text { modo que seja proporcionada a interaqção dos } \\
\text { pais com seus filhos na realização das } \\
\text { atividades. }\end{array}$ \\
\hline \multirow{3}{*}{$\begin{array}{l}\text { Assegurar o } \\
\text { desenvolvimen } \\
\text { to de aulas } \\
\text { interessantes } \\
\text { e desafiadoras }\end{array}$} & \begin{tabular}{|c|} 
Ampliar em $30 \%$ o uso dos \\
recursos pedagógicos disponíveis \\
na escola em 2016 , em $40 \%$ em \\
2017 e em $80 \%$ em 2018 . \\
\end{tabular} & $\begin{array}{l}\text { Fichas de controle diário de } \\
\text { retirada dos recursos } \\
\text { pedagógicos. }\end{array}$ & $\begin{array}{c}\text { Acompanhar, mensalmente, o planejamento } \\
\text { dos professores e observar os recursos } \\
\text { previstos e fazer indicações, quando } \\
\text { necessário. }\end{array}$ \\
\hline & $\begin{array}{c}\text { Realizar } 04 \text { reuniões com os } \\
\text { docentes, no a no de } 2016, \text { para } \\
\text { socialização de práticas } \\
\text { pedagógicas exitosas } \\
\text { desenvolvidas pelos mesmos. } \\
\end{array}$ & $\begin{array}{l}\text { Ata das reuniões com } \\
\text { respectivas assinaturas dos } \\
\text { participantes. }\end{array}$ & $\begin{array}{c}\text { Acompanhar, semanalmente, as aulas para } \\
\text { identificar boas práticas e, também, a } \\
\text { aplicação de práticas socializadas nas } \\
\text { reuniões }\end{array}$ \\
\hline & $\begin{array}{c}\text { Capacitar } 100 \% \text { dos docentes para } \\
\text { uso dos recursos pedagógicos } \\
\text { disponíveis na escola. }\end{array}$ & $\begin{array}{l}\text { Controle de presença nos } \\
\text { encontros de capacitação. }\end{array}$ & $\begin{array}{c}\text { Acompanhamento das pautas dos encontros } \\
\text { de capacitação e das aulas em todas as } \\
\text { turmas. }\end{array}$ \\
\hline \multirow{3}{*}{$\begin{array}{c}\text { Melhorar os } \\
\text { níveis de } \\
\text { proficiência } \\
\text { dos alunos em } \\
\text { LP e MA nos } \\
\text { anos de } \\
\text { escolaridade } \\
\text { avaliados pelo } \\
\text { SARESP }\end{array}$} & $\begin{array}{c}\text { Reduzir em } 60 \% \text { o percentual de } \\
\text { alunos no nível abaixo do básico } \\
\text { no } 2^{\text {a }} 3^{\text {a e }} 5 \text { ㅇ a nos de escolaridade } \\
\text { até } 2017 .\end{array}$ & $\begin{array}{l}\text { Avaliações bimestrais } \\
\text { Ata de conselho de classe } \\
\text { Relatório do grupo focal na } \\
\text { Avaliação Educacional. }\end{array}$ & $\begin{array}{l}\text { Análise dos itens de avaliações elaborados } \\
\text { pelos professores, confrontando-os com a } \\
\text { matriz de referência do SARESP para identificar } \\
\text { as habilidades exigidas. Acompanhamento do } \\
\text { planejamento dos profos para verificar se as } \\
\text { estratégias de ensino propiciam o } \\
\text { desenvolvimento de habilidades. }\end{array}$ \\
\hline & $\begin{array}{c}\text { Reduzir em } 40 \% \text { o n de alunos de } \\
1 \text { a ao } 5 \% \text { ano nas turmas de } \\
\text { recuperação no contraturno em } \\
2016 .\end{array}$ & $\begin{array}{l}\text { Lista de presença mensal das } \\
\text { turmas de recuperação } \\
\text { Ata de conselho de classe. }\end{array}$ & $\begin{array}{l}\text { Análise mensal das dificuldades a presentadas } \\
\text { pelos alunos, e das atividades ofe recidas pelos } \\
\text { profos, verificando se as mesmas auxiliam o } \\
\text { aluno a superar suas dificuldades. }\end{array}$ \\
\hline & $\begin{array}{c}\text { Ampliar em } 50 \% \text { o acervo de livros } \\
\text { paradidáticos da sala de leitura } \\
\text { até } 2017 .\end{array}$ & $\begin{array}{l}\text { Ficha de controle anual do } \\
\text { acervo de livros da sala de } \\
\text { leitura. }\end{array}$ & $\begin{array}{c}\text { Plano de Aplicação de Recursos Financeiro e } \\
\text { acompanhamento das guias de compras } \\
\text { semestrais. }\end{array}$ \\
\hline
\end{tabular}

\section{Continuidade do projeto}

A Formação Continuada em serviço é um meio de fortalecer e legitimar a escola como lócus de formação contínua e permanente, além de cumprimento da Lei n 9.394, de 20 de dezembro de 1996

Art. $61^{\circ}$. A formação de profissionais da educação, de modo a atender aos objetivos dos diferentes níveis e modalidades de ensino e às características de cada fase do desenvolvimento do educando, terá como fundamentos:

I - a associação entre teorias e práticas, inclusive mediante a capacitação em serviço; 
A continuidade do projeto, após o período e parcerias estabelecidos, será possível considerando que a escola possui como oportunidade (perspectiva externa) Indústrias da cidade que apoiam programas educacionais das escolas do município, como evidenciado na análise SWOT. Antes do término da parceria deste projeto, a Direção da escola contatará as indústrias com o perfil empreendedor em Educação para apresentar 0 atual projeto e seus resultados e estabelecer novas parcerias para a continuidade. Todavia, independente de parcerias, os Gestores Escolares estarão aptos a darem continuidade ao projeto, considerando o período de parceria com a Universidade Municipal de Educação de São Caetano do Sul.

\section{Marketing e Comunicação}

\section{Lançamento do projeto}

Será realizado workshop, aberto à comunidade escolar, com palestra. O projeto "Formação Continuada no Cotidiano Escolar" será lançado na reunião pedagógica para toda equipe docente, público alvo do projeto, com a participação da Direção da Escola, membros da Universidade Municipal de Educação de São Caetano do Sul, da Fundação NOVO BRASIL - Programa de Melhoria da Aprendizagem e Diretoria Local do SESI de São Caetano do Sul. Os convidados serão contatados, com antecedência, para verificar a disponibilidade de agenda e definição da data. Será entregue um comunicado para todos os professores, via correio, com aviso de recebimento, com vinte dias de antecedência, informando a data da reunião pedagógica e o lançamento do projeto "Formação Continuada no Cotidiano Escolar" com as seguintes informações:

- Possibilidades de enriquecimento do currículo profissional e aperfeiçoamento, durante sua jornada de trabalho contratual.

- Parceria com a Instituição NOVO BRASIL - Programa de Melhoria da Aprendizagem para desenvolvimento de ações formativas na escola.

- O benefício de contar com profissionais externos à escola, evidenciando que conhecimento já está disponível no mercado e circulando entre os profissionais da Educação.

- Resultados alcançados por outras instituições, por meio da parceria com a Novo Brasil.

- Na reunião de pais haverá comunicação do projeto e os benefícios que trará para os alunos.

\section{Canais de comunicação e acompanhamento do projeto}

\section{Marketing interno}

Durante o desenvolvimento do projeto será utilizado os seguintes canais de comunicação interna para envolvimento da equipe docente:

- Correio eletrônico institucional - mensal - com informações das datas dos próximos encontros de formação e a avaliação de satisfação dos encontros do último período e as providências adotadas, quando necessário.

- Jornal mensal de circulação interna com informações dos temas a serem desenvolvidos nas formações docentes do próximo período.

- Cartazes semanais com frases motivacionais e, também, curiosidades vinculadas aos temas a serem estudados nos encontros da semana.

\section{Marketing externo}

A comunidade escolar e público em geral terão acesso as informações do projeto por meio dos seguintes canais:

- Site da escola com o resumo do projeto e a cada semana será alimentado com os temas em estudo.

- Jornal do bairro de circulação semanal com fotos e notícias dos encontros de formação ocorridos na semana anterior.

- Faixa permanente na entrada da escola anunciando a parceria entre SESI e a Universidade Municipal de Educação, por meio do NOVO BRASIL, com troca trimestral devido ao desgaste do material. 


\section{Divulgação de resultados}

O projeto será avaliado e monitorado por meio de reuniões mensais entre a equipe gestora e equipe docente, pesquisas semestrais com alunos, docentes e confrontadas com os indicadores previstos nos objetivos estratégicos.

As reuniões mensais entre gestores e docentes objetivarão discutir as implementações realizadas no planejamento das aulas, a partir das formações e sistematizar ações comuns que serão incorporadas no projeto político pedagógico da escola. As observações das aulas realizadas sistematicamente pelo coordenador pedagógico retroalimentarão as referidas discussões.

As pesquisas com professores objetivarão verificar a satisfação com as Formações e com os alunos, verificar as mudanças na prática docente e os impactos na aprendizagem. Estes resultados serão analisados e confrontados com os relatórios de observação de aula do coordenador pedagógico, com as fichas de controle de empréstimo de livros da biblioteca pelos alunos, de retirada de recursos pedagógicos pelos professores, além dos relatórios de desempenho dos alunos nas avaliações internas. Os resultados serão sistematizados em apresentações com gráficos para divulgação.

Os resultados parciais do projeto serão divulgados no jornal da escola, no site e no Seminário aberto à comunidade escolar, a ser realizado ao final de cada semestre do projeto, (são três no total) com palestra do Reitor da Universidade de Educação de São Caetano do Sul que abordará assuntos alusivos ao tema "Formação Contínua no Cotidiano Escolar".

\section{Equipe do Projeto}

\section{Equipe interna}

Estão relacionados no quadro abaixo os componentes da equipe interna:

\begin{tabular}{|c|c|c|c|c|}
\hline Cargo & Formação & $\begin{array}{c}\text { Tempo na } \\
\text { escola }\end{array}$ & Experiência anterior & $\begin{array}{c}\text { Responsável } \\
\text { pelas } \\
\text { atividades: }\end{array}$ \\
\hline $\begin{array}{c}\text { Diretor de } \\
\text { Escola }\end{array}$ & Pedagogia & 5 anos & $\begin{array}{c}\text { Coordenador } \\
\text { Pedagógico }\end{array}$ & $\begin{array}{c}1.1 ; 1.2 ; 2.1 ; \\
2.2 ; 4.1\end{array}$ \\
\hline $\begin{array}{c}\text { Coordenador } \\
\text { Pedagógico }\end{array}$ & Pedagogia & 8 anos & $\begin{array}{c}\text { Professor de Ensino } \\
\text { Fundamental }\end{array}$ & $\begin{array}{c}1.1 ; 1.2 ; 3.1 ; \\
3.2 ; 3.3 ; 4.1\end{array}$ \\
\hline $\begin{array}{c}\text { Coordenador } \\
\text { Pedagógico }\end{array}$ & Pedagogia & 3 anos & $\begin{array}{c}\text { Professor de Ensino } \\
\text { Fundamental }\end{array}$ & $3.1 ; 3.2 ;$ \\
\hline
\end{tabular}




\section{Teresa Manfreda}

Profissionais externos

\begin{tabular}{|c|c|c|}
\hline Tipo de profissional & Competências necessárias & Participação no projeto \\
\hline Formador & $\begin{array}{c}\text { Conhecimento procedimental na } \\
\text { metodologia de ensino sócio- } \\
\text { interacionaista }\end{array}$ & $\begin{array}{c}\text { Formação para os } \\
\text { Docentes }\end{array}$ \\
\hline Formador & $\begin{array}{c}\text { Conhecimento sobre o processo de } \\
\text { aprendizagem na abordagem sócio- } \\
\text { interacionaista }\end{array}$ & $\begin{array}{c}\text { Formação para os } \\
\text { Docentes }\end{array}$ \\
\hline Formador & $\begin{array}{c}\text { Conhecimento procedimental em } \\
\text { avaliação da aprendizagem - com } \\
\text { foco na formativa }\end{array}$ & $\begin{array}{c}\text { Formação para os } \\
\text { Docentes }\end{array}$ \\
\hline Estatístico & $\begin{array}{c}\text { Conhecimento em pedagógica e } \\
\text { elaboração e análise de pesquisa de } \\
\text { satisfação e de impacto. }\end{array}$ & $\begin{array}{c}\text { Monitoramento e avaliação } \\
\text { do projeto }\end{array}$ \\
\hline Palestrante & $\begin{array}{c}\text { Conhecimento em Formação } \\
\text { Contínua em Serviço }\end{array}$ & Palestra nos Seminários \\
\hline
\end{tabular}

\section{Plano financeiro}

Investimentos (despesas de capital)

\begin{tabular}{|c|c|c|c|}
\hline Material permanente & Ano 1 & Ano 2 & Ano 3 \\
\hline $\begin{array}{c}\text { Tablet 16 GB com wi-fi } \\
\text { tela 10 polegadas }\end{array}$ & $20.000,00$ & 0,00 & 0,00 \\
\hline Projetor Multimidia & $3.000,00$ & & $\mathbf{0 , 0 0}$ \\
\hline Total & $\mathbf{2 3 . 0 0 0 , 0 0}$ & $\mathbf{0 , 0 0}$ & \\
\hline
\end{tabular}

\section{Despesas correntes}

\begin{tabular}{|c|c|c|c|}
\hline Material de consumo & Ano 1 & Ano 2 & Ano 3 \\
\hline $\begin{array}{c}\text { Cavalete flip-chart com } \\
\text { quadro e papel }\end{array}$ & 600,00 & 0,00 & 0,00 \\
\hline $\begin{array}{c}\text { Folhas de papel para flip } \\
\text { chart }\end{array}$ & & 300,00 & 200,00 \\
\hline Papelo Sulfite A4 & & 400,00 & 300,00 \\
\hline Total & $\mathbf{6 0 0 , 0 0}$ & $\mathbf{7 0 0 , 0 0}$ & $\mathbf{5 0 0 , 0 0}$ \\
\hline
\end{tabular}

\begin{tabular}{|c|c|c|c|}
\hline Gastos com locomoção & Ano 1 & Ano 2 & Ano 3 \\
\hline & 0,00 & 0,00 & 0,00 \\
\hline Total & $\mathbf{0 , 0 0}$ & $\mathbf{0 , 0 0}$ & $\mathbf{0 , 0 0}$ \\
\hline
\end{tabular}

\begin{tabular}{|c|c|c|c|}
\hline Serviços de terceiros & Ano 1 & Ano 2 & Ano 3 \\
\hline Palestrante-Formador & & $14.200,00$ & $8.100,00$ \\
\hline Estatístico & & $6.100,00$ & $4.050,00$ \\
\hline Palestrante & & $1.000,00$ & $1.000,00$ \\
\hline Total & $\mathbf{0 , 0 0}$ & $\mathbf{2 1 . 3 0 0 , 0 0}$ & $\mathbf{1 3 . 1 5 0 , 0 0}$ \\
\hline
\end{tabular}


Recursos totais

\begin{tabular}{|c|c|c|c|c|}
\hline Tipo de item & Ano 1 & Ano 2 & Ano 3 & Total \\
\hline Despesas de Capital & $\mathbf{2 3 . 0 0 0 , 0 0}$ & $\mathbf{0 , 0 0}$ & $\mathbf{0 , 0 0}$ & $\mathbf{0 , 0 0}$ \\
\hline Obras e infraestrutura & & & & \\
\hline Material permanente & $23.000,00$ & & & $23.000,00$ \\
\hline Despesas Correntes & 600,00 & 700,00 & 500,00 & $1.800,00$ \\
\hline Material de consumo & 600,00 & 700,00 & 500,00 & $1.800,00$ \\
\hline Gastos com locomoção & & & & \\
\hline Serviços de terceiros & & $21.300,00$ & $13.150,00$ & $38.450,00$ \\
\hline Total de recursos do edital & $\mathbf{2 3 . 6 0 0 , 0 0}$ & $\mathbf{2 2 . 0 0 0 , 0 0}$ & $13.650,00$ & $\mathbf{5 9 . 2 5 0 , 0 0}$ \\
\hline Gastos adicionais & 0,00 & $\mathbf{0 , 0 0}$ & $\mathbf{0 , 0 0}$ & $\mathbf{0 , 0 0}$ \\
\hline Recursos totais & $\mathbf{2 3 . 6 0 0 , 0 0}$ & $\mathbf{2 2 . 0 0 0 , 0 0}$ & $\mathbf{1 3 . 6 5 0 , 0 0}$ & $\mathbf{5 9 . 2 5 0 , 0 0}$ \\
\hline
\end{tabular}

De acordo com o Edital N 11 - Projetos Inovadores em Educação, da Fundação NOVO BRASIL - Educação para o Futuro, o valor necessário para viabilização do projeto se enquadra na categoria $C$ (Mínimo de $R \$$ 50.000 e máximo de $\mathrm{R} \$ 74.999,99)$ para despesas de capital e correntes, conforme explicitado na tabela acima.

\section{Fontes de recursos}

\begin{tabular}{|c|c|}
\hline Fonte & Valor \\
\hline PNAE - Programa Nacional de Alimentação Escolar & 728,80 \\
\hline APM - Associação de Pais e Mestres & 437,28 \\
\hline Recursos totais & $\mathbf{1 . 1 6 6 , 0 8}$ \\
\hline
\end{tabular}

\section{Contrapartida}

Durante o projeto, os docentes serão convocados em 6 sábados, com pagamento de 6 horas extras por sábado, para participarem do Evento Saber em Ação, com o objetivo de socializarem boas práticas em sala de aula, a partir dos estudos realizados no projeto.

\begin{tabular}{|c|c|c|c|}
\hline Profissionais & $\begin{array}{c}\text { Horas } \\
\text { dedicadas ao } \\
\text { projeto }\end{array}$ & $\begin{array}{c}\text { Valor } \\
\text { médio/hora }\end{array}$ & $\begin{array}{c}\text { Contrapartida } \\
\text { por profissional }\end{array}$ \\
\hline 16 Docentes & 36 & 10,78 & 388,08 \\
\hline Total de contrapartida & $\mathbf{3 6}$ & - & $\mathbf{6 . 2 0 9 , 2 8}$ \\
\hline
\end{tabular}

Fonte: Diretoria de Recursos Humanos SESI-SP 